\title{
Effect of Fungicides on Phosphate Solubilization by Klebsiella oxytoca and Enterobacter ludwigii
}

\author{
Buddhi Charana Walpola, Mi-Jung Keum, and Min-Ho Yoon* \\ Department of Bio-Environmental Chemistry, College of Agriculture and Life Sciences, Chungnam National University, \\ Daejeon, 305-764, Korea.
}

\begin{abstract}
The aim of the present study was to isolate phosphate solubilizing bacteria (PSB) and to assess their potential tolerance to fungicides. Out of thirty PSB, two strains Klebsiella oxytoca and Enterobacter ludwigii were selected on the basis of their tolerance to fungicides. Both strains were assessed for their phosphate solubilizing ability using three different fungicides (difenoconazole, fluazinam and streptomycin) each with the concentrations of $0,1,2$ or 3 times of the recommended rate. Both strains showed increased phosphate solubilization with difenoconazole at 1,2 and 3 times of the recommended rate as compared to the phosphate solubilization of the control. The phosphate solubilization in Klebsiella oxytoca was recorded as 326, 538, 518 and $481 \mu \mathrm{g} \mathrm{mL}^{-1}$ at $0,1,2$ and 3 times of the recommended rate respectively, whereas in Enterobacter ludwigii it was recorded as $395,499,529$ and $533 \mu \mathrm{g} \mathrm{mL}^{-1}$ respectively at various doses. Based on the present findings, it may be concluded that both strains have the potential to be used as bio-inoculants which can solubilize phosphate even at the higher doses as compared to the recommended rate of fungicides.
\end{abstract}

Key words: Phosphate solubilization, Fungicides, Klebsiella oxytoca, Enterobacter ludwigii, Difenoconazole, Fluazinam, Streptomycin

\section{Introduction}

Use of agrochemicals (such as fertilizers, pesticides, soil conditioners and phytohormones) aiming at optimizing crop production has become very common in agriculture (Ahemad and Khan, 2011). Pesticides, the major plant protection agents include a wide range of compounds including insecticides, fungicides, bactericides, herbicides, rodenticides, molluscicides and nematicides (Aktar et al., 2009). Use of pesticides increased by 3 -fold over the past several decades due to intensified agricultural systems (Fox et al., 2007).

Many pesticides showed no detectable effects on soil microorganisms at the recommended application rates. However, application at increased rates is often reported as most of the farmers decide based on their own experience of the effective pest control. Repeated and overuse of pesticides in agriculture is a matter of concern because these chemicals are recognized as a source of potential adverse impacts on the metabolic activities of soil microorganisms as well as their plant growth promoting characteristics (Wani et al., 2005;

\footnotetext{
Received : 2013. 1. 10 Accepted : 2013. 2. 25

*Corresponding author : Phone: +82428217888

E-mail: mhyoon@cnu.ac.kr
}

Ahemad et al., 2009).

Some microorganisms (called as phosphate solubilizing microorganisms-PSMs) perform phosphate solubilization. Their growth and phosphate solubilizing activity may also be affected by the pesticides leading to the imbalance phosphorous nutrition for the crop plants. However, the effect of pesticides on microbial growth and their activity especially phosphate solubilization can only be assessed using microorganisms which are tolerant to the pesticide of concern (Oves et al., 2009). Under this background, in the present investigation, an attempt has been made to examine the effects of different fungicides applied at various rates on Klebsiella oxytoca and Enterobacter ludwigii, the two phosphate solubilizing bacteria.

\section{Materials and Methods}

Isolation of phosphate solubilizing microorganisms Phosphate solubilizing microorganisms used in this study were isolated from the soils collected from green houses in Chungcheongnam-do, Gongju-gun area and abounded mines of Boryeong area in South Korea. In order to isolate, a serial dilution assay was carried out in $0.85 \% \mathrm{NaCl}$ solution and $10 \mu \mathrm{l}$ of 
diluted suspension was spread on NBRIP medium (National Botanical Research Institute Phosphate medium) containing $10 \mathrm{~g}$ glucose, $5 \mathrm{~g} \mathrm{Ca}_{3}\left(\mathrm{PO}_{4}\right)_{2}, 5 \mathrm{~g} \mathrm{MgCl} 2.6 \mathrm{H}_{2} \mathrm{O}$,

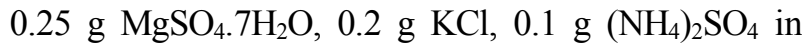
1 L distilled water (Nautiyal, 1999). The plates were incubated for 7 days at $30^{\circ} \mathrm{C}$. Morphologically distinct colonies with clear halos were purified by repeated sub-culturing. A total 30 phosphate solubilizing bacterial strains were isolated with maximum halo size and maintained on solid NBRIP agar medium until use.

\section{Assessment of bacterial strains for fungicide tolerance}

Three fungicides namely difenoconazole, fluazinam and streptomycin (Table 1) were selected for the study considering their widespread usage in agricultural fields in S. Korea. The isolated phosphate solubilizing bacterial strains were tested for their tolerance to each fungicide by agar plate dilution method using minimal salt agar medium containing $1 \mathrm{~g} \mathrm{KH}_{2} \mathrm{PO}_{4}, 1 \mathrm{~g} \mathrm{~K} \mathrm{HPO}_{4}$, $1 \mathrm{NH}_{4} \mathrm{NO}_{3}, 0.2 \mathrm{~g} \mathrm{MgSO}_{4} .7 \mathrm{H}_{2} \mathrm{O}, 0.02 \mathrm{~g} \mathrm{CaCl}_{2} .2 \mathrm{H}_{2} \mathrm{O}$, $0.01 \mathrm{~g} \mathrm{FeSO}_{4} .7 \mathrm{H}_{2} \mathrm{O}$ in $1 \mathrm{~L}$ distilled water (Ahemad and Khan, 2009). Fungicides (1X, 2X and $3 X$ of the recommended rate of each fungicide) containing freshly prepared agar plates were spot inoculated with $10 \mu \mathrm{l}$ of $10^{8}$ cells $\mathrm{ml}^{-1}$ of bacterial strains. The plates were incubated for 3 days at $30^{\circ} \mathrm{C}$ and bacterial growth was checked daily up to 3 days. Out of 30 phosphate solubilizing bacterial isolates, 2 bacterial isolates showing relatively higher growth rates against fungicides were selected for further studies.

\section{Assay of inorganic phosphate solubilizing abilities} Bacterial strains were grown in sterilized liquid NBRIP medium $(20 \mathrm{~mL})$ at $30^{\circ} \mathrm{C}$ for 2 days with continuous shaking at $150 \mathrm{r} \mathrm{min}^{-1}$. Aliquots of culture $(1 \mathrm{ml}$ of $10^{8}$ cells $\mathrm{mL}^{-1}$ ) was then transferred to a $500 \mathrm{~mL}$ flask $(n=3$ per strain) containing sterilized liquid NBRIP medium $(250 \mathrm{~mL})$ supplemented with $0,1,2$ and 3 times of the recommended rate of each fungicide. The flasks were incubated with continuous shaking at 3 $0^{\circ} \mathrm{C}$. A sample of culture broth $(10 \mathrm{~mL})$ from each cultured flask was removed and centrifuged at 8000 rpm for $15 \mathrm{~min}$. The clear supernatant was used in determining the amount of phosphorous released into the medium. The $\mathrm{pH}$ of the culture medium was also recorded with the $\mathrm{pH}$ meter equipped with glass electrode. The phosphorus availability was determined using phospho-molybdate blue color method (Murphy and Riley, 1962).

\section{Results and Discussion}

In the present study, out of 30 phosphate solubilizing isolates Klebsiella oxytoca and Enterobacter ludwigii grew well with varying concentrations of all tested fungicides and showed a variable tolerance in minimal salt agar medium. The response of microorganisms to different pesticides is considered to be regulated at physiological and genetic level. Therefore, microbial resistance to a pesticide was linked with their capacity to degrade it (Kumar et al., 1996; Ortiz-Herna'ndez and Sa'nchez-Salinas, 2010). As reported by Bellinaso et al. (2003), the resistance can be temporal or permanent, where physiological changes occur as the temporal tolerance mechanisms to alleviate the inhibitory effects of the pesticide. Permanent resistance, on the other hand, is expected as a result of genetic modifications, inherited by the subsequent generation of microbes (Herman et al., 2005; Johnsen et al., 2001).

Fig. 1, 2 and 3 show the effect of various concentrations of fungicides on phosphate solubilization of Klebsiella oxytoca and Enterobacter ludwigii. Strains showed diverse levels of phosphate solubilizing activity in the presence of various fungicides.

Both strains showed the increased phosphate solubili-

Table 1. Fungicides used in the study.

\begin{tabular}{|c|c|c|c|}
\hline Common name & Chemical name & Chemical family & Recommended dose \\
\hline Difenoconazole & $\begin{array}{l}\text { Cis-trans-3-chloro-4-[4-methyl-2-(1H-1, 2, 4-triazol-1- } \\
\text { ylmethyl)-1, 3-dioxolan-2-yl]phenyl 4-chlorophenyl ether }\end{array}$ & Triazole & $0.5 \mathrm{~mL} \mathrm{~L}^{-1}$ \\
\hline Fluazinam & $\begin{array}{l}\text { 3-chloro-N-(3 chloro-5-trifluoromethyl-2-pyridyl)- } \alpha \quad \alpha \alpha \\
\text {-trifluoro-2,6-dinitro- } \rho \text {-toluidine }\end{array}$ & Dintroaniline & $0.5 \mathrm{~g} \mathrm{~L}^{-1}$ \\
\hline Streptomycin & $\begin{array}{l}\text { O-2-deoxy-2-methylamino- } \alpha \text {-L-glucopyranosyl-(1 to } 2) \text { - } \\
\text { O-5-deoxy-3-C-formyl- } \alpha \text {-L-lyxofuranosyl-(1 to } 4)-\mathrm{N} 3 \text {, N3- } \\
\text { diamidino-D-streptamine-sulfate }\end{array}$ & Antibiotics & $0.5 \mathrm{~g} \mathrm{~L}^{-1}$ \\
\hline
\end{tabular}


zation with difenoconazole at various doses of the pesticide (Fig. 1), higher as compared to the control. The values for phosphate solubilization by Klebsiella oxytoca were recorded as 326, 538, 518 and $481 \mu \mathrm{g}$ $\mathrm{mL}^{-1}$ for $0,1,2$ and 3 times of the recommended rate respectively, whereas for Enterobacter ludwigii it was recorded as $395,499,529$ and $533 \mu \mathrm{g} \mathrm{mL}^{-1}$ respectively for the different doses. The results were in agreement with Ramani (2011) who reported enhancement in phosphate solubilization by Bacillus spphaericus and Pseudomonas cepacia respectively with chlorpyripos and monochrotophos at $1 \mathrm{X}$ and $2 \mathrm{X}$ of the recommended rate. Narison (1995) also reported similar results with chlorpyriphos and quinalphose by Aspergillus aculeatus. There are some reports about microorganisms which could degrade complex compounds in pesticides. Microbes used these compounds as their carbon and energy sources. Sangodkar et al. (1998) and MacLoughlin et al. (1992) reported that $P$. cepacia had the ability to

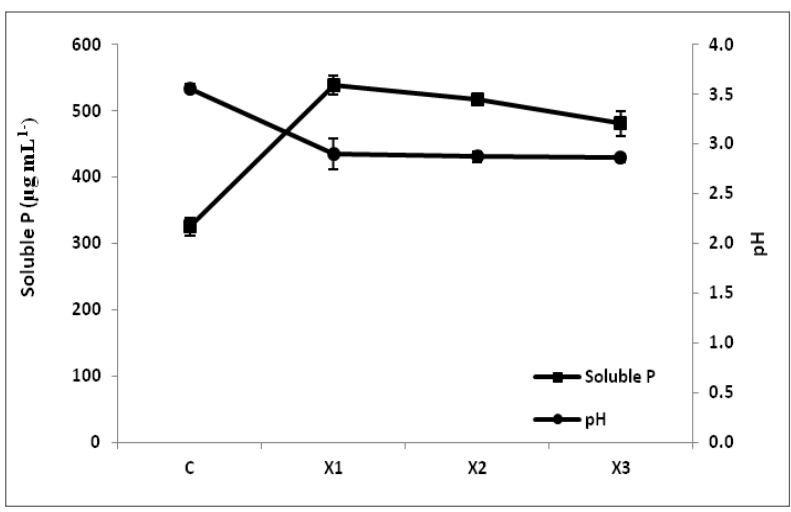

(a)

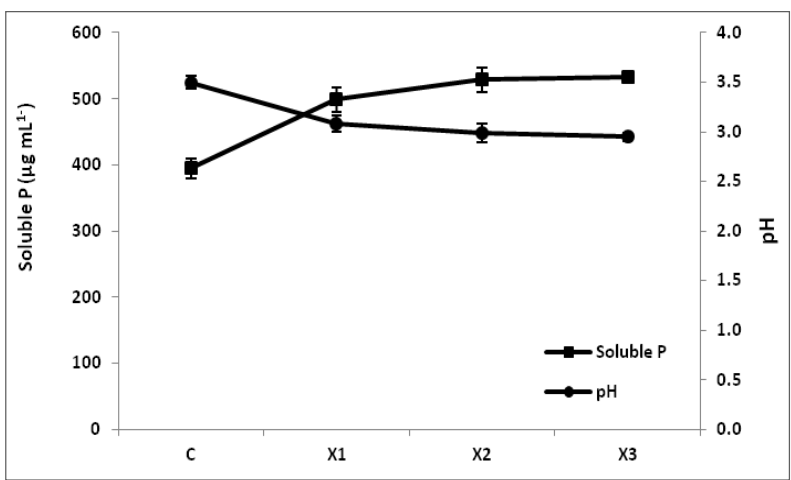

(b)

Fig. 1. Effect of Difenoconazole on phosphate solubilization and pH change by (a) Klebsiella oxytoca (b) Enterobacter ludwigii. C- Control (without fungicide), X1, X2 and X3 represent $1 \mathrm{X}, 2 \mathrm{X}$ and $3 \mathrm{X}$ of the recommended rate of fungicide respectively. Values given here are the means $(n=$ 3) \pm standard deviation. degrade chlorinated aromatic substances present in complex pesticides and herbicides. Sopid (2012) isolated novel atrazine degrading Klebsiella $s p$. from a long term atrazine treated sugarcane field.

Fig. 2 shows the effect of various concentrations of fluazinam on phosphate solubilization by Klebsiella oxytoca and Enterobacter ludwigii. Phosphate solubilization by Klebsiella oxytoca decreased with increasing concentrations of fluazinam from 1 to 3 times of the recommended rate. It was decreased by $19 \%, 29 \%$ and $32 \%$ respectively for the fluazinam concentrations of 1, 2 and 3 times of the recommended rate compared to the control. However, there was no significant reduction $(\mathrm{P} \leq 0.05)$ in phosphate solubilization by Enterobacter ludwigii with increasing fluazinam concentrations and it ranged from $395 \mu \mathrm{g} \mathrm{mL}^{-1}$ for the control to $384 \mu \mathrm{g} \mathrm{mL}^{-1}$ for 3 times of the recommended rate of fluazinam.

Fig. 3 shows the effect of various concentrations of

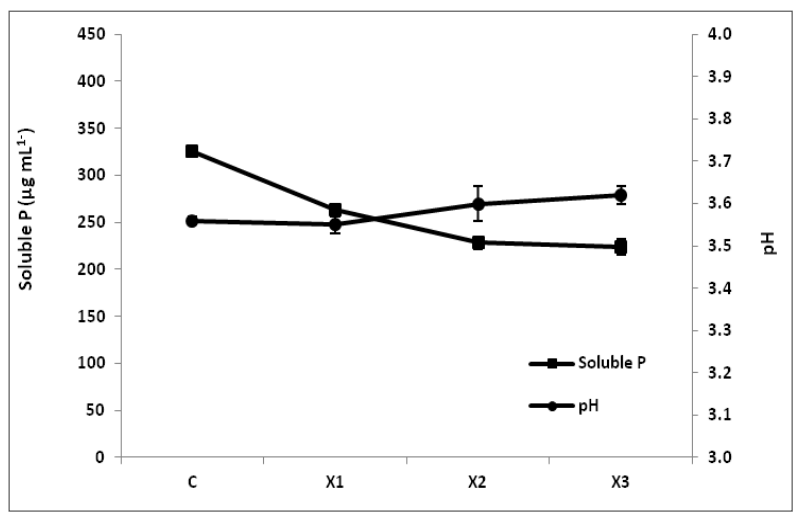

(a)

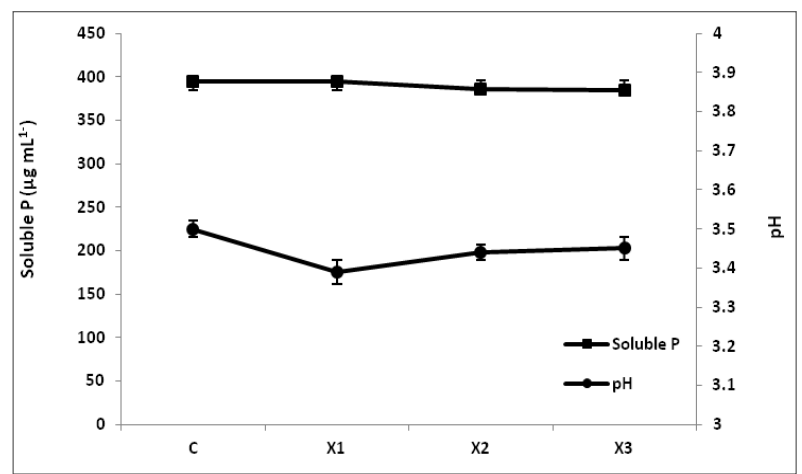

(b)

Fig. 2. Effect of Fluazinam on phosphate solubilization and pH change by (a) Klebsiella oxytoca (b) Enterobacter ludwigii. C- Control (without fungicide), X1, X2 and X3 represent 1X, 2X and $3 X$ of the recommended rate of fungicide respectively. Values given here are the means $(n=$ 3) \pm standard deviation. 
streptomycin on phosphate solubilization by Klebsiella oxytoca and Enterobacter ludwigii. Similar to fluazinam, phosphate solubilization by Klebsiella oxytoca decreased with increasing concentrations of streptomycin from 1 to 3 times of the recommended rate. However, there was no significant reduction $(\mathrm{P} \leq 0.05)$ in phosphate solubilization at the recommended rate compared to the control. However, phosphate solubilization by Enterobacter ludwigii decreased by $40 \%, 50 \%$ and $52 \%$ respectively for the streptomycin concentrations at $1 \mathrm{X}, 2 \mathrm{X}$ and $3 \mathrm{X}$ of the recommended rate compared to the control. The decrease in phosphate solubilization with fluazinam and streptomycin probably may be due to the impairment of various metabolic activities of the organisms (Kumar et al., 2010).

However, comparatively to the present values, Ahemad and Khan (2012a) reported severe reductions in phosphate solubilization $(94 \%, 91 \%, 89 \%$ and $83 \%$ at $3 \mathrm{X}$ of the recommended rates of tebuconazole, hexaconazole, metalaxyl and kitazin respectively) by

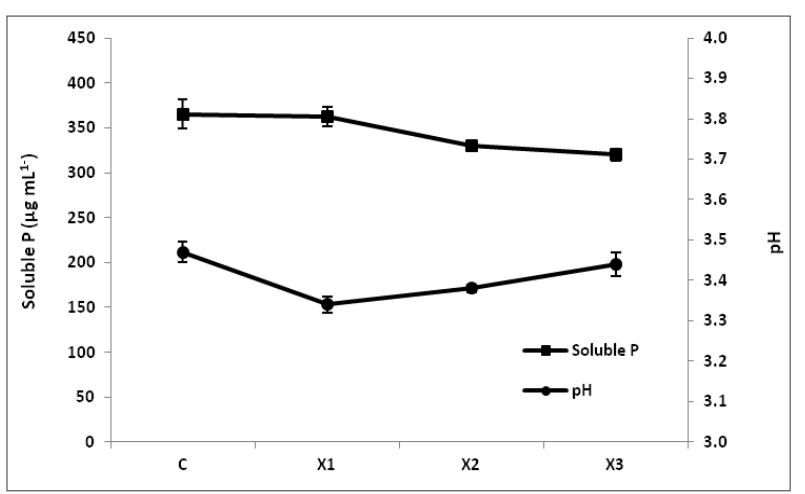

(a)

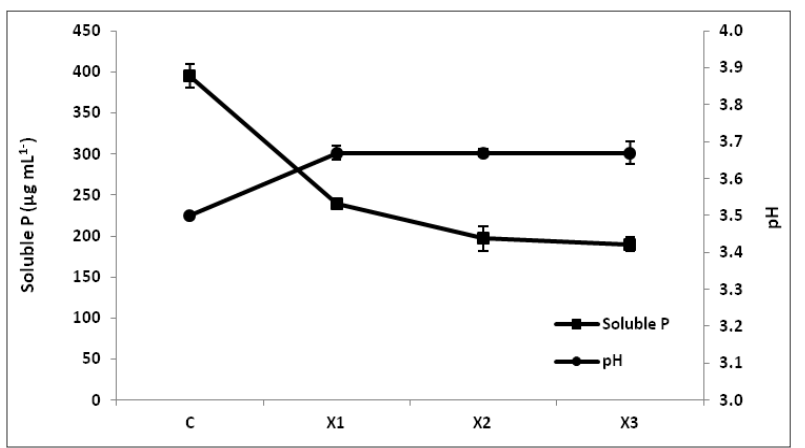

(b)

Fig. 3. Effect of Streptomycin on phosphate solubilization and pH change by (a) Klebsiella oxytoca (b) Enterobacter ludwigii. C- Control (without fungicide), X1, X2 and X3 represent 1X, 2X and $3 X$ of the recommended rate of fungicide respectively. Values given here are the means $(n=$ 3) \pm standard deviation.
Klebsiella $s p$. isolated from mustard rhizosphere. In a separate study, the same authors (Ahemad and Khan, 2012b) observed more or less similar reduction in phosphate solubilization $(95 \%, 94 \%, 94 \%$ and $82 \%$ at $3 \mathrm{X}$ of the recommended rate of metalaxyl, tebuconazole, hexaconazole, and kitazin respectively) by Pseudomonas putida isolated from mustard rhizosphere. Therefore, in contrast, both strains of the present study showed considerably high phosphate solubilizing potential even at the higher doses of the fungicides.

The negative relationship between $\mathrm{pH}$ and phosphate solubilization was observed in all the experiments. Decrease in medium $\mathrm{pH}$ accompanied by phosphate solubilization may indicate that lowering $\mathrm{pH}$ of the medium through organic acid production may be the possible mechanism for phosphate solubilization as reported by other researchers as well (Yasmin and Banu, 2011; Yu et al., 2011).

\section{Conclusion}

Both strains showed phosphate solubilizing potential even at the higher doses over the recommended rates of fungicides. Furthermore, strains showed relatively higher phosphate solubilization with difenoconazole than the other pesticides tested. Therefore, these fungicide tolerant strains as bio-inoculants would have attractive beneficial impacts on sustainable agricultural practices. Field studies with an assessment on the effect of fungicides on the other plant growth promoting activities of the strains would still be needed in exploring the potential agricultural significance of the strains further.

\section{References}

Ahemad, M. and M.S. Khan. 2009. Effect of insecticidetolerant and plant growth promoting Mesorhizobium on the performance of chickpea grown in insecticide stressed alluvial soils. J. Crop Sci. Biotechnol. 12:213-222.

Ahemad, M. and M.S. Khan. 2011. Pseudomonas aeruginosa strain PS1enhances growth parameters of greengram [Vigna radiata (L.) Wilczek] in insecticide-stressed soils. J. Pest Sci. 84:123-131.

Ahemad, M. and M.S. Khan. 2012a. Biotoxic impact of fungicides on plant growth promoting activities of phosphate solubilizing Klebsiella sp. Isolated from mustard (Brassica campestris) rhizosphere. J. Pest Sci. 85:29-36.

Ahemad, M. and M.S. Khan. 2012b. Effect of fungicides on plant growth promoting activities of phosphate solubilizing 
Pseudomonas putida isolated from mustard (Brassica compestris) rhizosphere. Chemosphere. 86:945-950.

Aktar, W., D. Sengupta, and A. Chowdhury. 2009. Impact of pesticides use in agriculture: their benefits and hazards. Interdiscip. Toxicol. 2:1-12.

Bellinaso, M.L., C.W. Greer, M.C. Peralba, J.A. Henriques, and C.C. Gaylarde. 2003. Biodegradation of the herbicide trifluralin by bacteria isolated from soil. FEMS Microb. Ecol. 43:191-194.

Fox, J. E., J. Gulledge, E. Engelhaupt, M.E. Burow, and J.A. McLachlan. 2007. Pesticides reduce symbiotic efficiency of nitrogen-fixing rhizobia and host plants. Proc. Natl. Acad. Sci. USA. 104:10282-10287.

Herman, P.L., M. Behrens, S. Chakraborty, B.M. Crastil, J. Barycki, and D.P. Weeks. 2005. A three component dicamba O-demethylase from Pseudomonas maltiphilia strain DI-6: gene isolation, characterization and heterologous expression. J. Biol. Chem. 280:24759-24767.

Johnsen, K., C.S. Jacobsen, V. Torsvik, and J. Sorensen. 2001. Pesticide effects on bacterial diversity in agricultural soils-a review. Biol. Fert. Soils. 33:443-453.

Kumar, N., J.I. Anubhuti Bora, and M.K. Amb. 2010. Chronic toxicity of the triazole fungicide tebuconazole on a heterocystous, nitrogenfixing rice paddy field cyanobacterium, Westiellopsis prolific Janet. J. Microbiol. Biotechnol. 20: 1134-1139.

Kumar, S., K.G. Mukerji, and R. Lal. 1996. Molecular aspects of pesticide degradation by microorganisms. Crit. Rev. Microbiol. 22:1-26.

MacLoughlin, T., J. Quinn, and A. Bettermann. 1992. Pseudomonas cepacia suppression of sunflower wilt fungus and role of antifungal compounds in controlling disease. Appl. Environ. Microbiol. 58:1760-1763.

Murphy, J. and J.P. Riley. 1962. A modified single solution method for the determination of phosphate in natural waters. Anal. Chem. Acta. 27:31-36.

Narison, V. and H.H. Patel. 1995. Studies on phosphate solubilizing microbes with special reference to fungi.
$\mathrm{PhD}$ thesis. Bhavnagar University, Gujarat, India.

Nautiyal, C. S. 1999. An efficient microbiological growth medium for screening phosphate solubilizing microorganisms. FEMS Microbiol. Lett. 170:265-270.

Ortiz-Herna'ndez ML, Sa'nchez-Salinas E (2010) Biodegradation of the organophosphate pesticide tetrachlorvinphos by bacteria isolated from agricultural soils in Me'xico. Rev Int Contam Ambient 26:27-38.

Oves, M., A. Zaidi, M.S. Khan, and M. Ahemad. 2009. Variation in plant growth promoting activities of phosphatesolubilizing microbes and factors affecting their colonization and solubilizing efficiency in different agro-ecosystems. In: Khan MS, Zaidi A (eds) Phosphate solubilizing microbes for crop improvement. Nova Science, New York, pp 247263.

Ramani, V. 2011. Effect of pesticides on phosphate solubilization by Bacillus sphaericus and Pseudomonas cepacia. Pestic. Biochem. Physiol. 99:232-236.

Sangodkar, U., P. Chapman, and A. Chakrabarty. 1998. Cloning, physical mapping and expression of chromosomal genes specifying degradation of the herbicide $2,4,5-\mathrm{T}$ by Pseudomonas cepacia AC1100, Gene. 71:267-277.

Sopid, S. 2012. Characterization of novel atrazine degrading Klebsiella sp. isolated from Thai agricultural soil. World Acad. Sci. Eng. Technol. 68: 1656-1658.

Wani, P.A., A. Zaidi, A.A. Khan, and M.S. Khan. 2005. Effect of phorate on phosphate solubilization and indole acetic acid releasing potentials of rhizospheric microorganisms. Ann. Plant Prot. Sci. 13:139-144.

Yasmin, H. and A. Bano. 2011. Isolation and characterization of phosphate solubilizing bacteria from rhizosphere soil of weeds of Khewra salt range and Atock. Pakistan J. Bot. 43: 1663-1668.

Yu, X., X. Liu, T.H. Zhu, G.H. Liu, and C. Mao. 2011. Isolation and characterization of phosphate solubilizing bacteria from walnut and their effect on growth and phosphorus mobilization. Biol. Fert. Soils. 47:437-446. 